\title{
Morbidity associated with pelvic inflammatory disease
}

\author{
MICHAEL W ADLER, ELIZABETH H BELSEY, AND BRENDAN H O'CONNOR \\ From the Academic Department of Genitourinary Medicine, Middlesex Hospital Medical School, London
}

SUMMARY To identify the long-term sequelae and morbidity associated with acute pelvic inflammatory disease (PID) patients with acute PID and matched controls were interviewed at five-monthly intervals for about 21 months after entry into the study. In some instances morbidity among the patients was increased, particularly at five months after admission to hospital. Significantly more patients than controls had visited hospital as outpatients, been admitted to hospital and undergone abdominal operations, and had to alter their normal daily routine and take time off work. The cumulative rates for all of these, except for time off work, were significantly higher in the patients than in the controls. Differences between the two groups both at early and later interviews and cumulatively were evident in the incidence of abdominal pain (other than menstrual pain), change in menstruation (longer and more painful), and pain during sexual intercourse, which persisted in one-fifth of patients after the initial acute episode.

\section{Introduction}

The relative ease of cure of most of the sexually transmitted diseases (STDs) detracts from the major contemporary problems associated with them, such as acute and chronic pelvic inflammatory disease (PID), infertility, the possible association with carcinoma of the cervix, and anxiety. PID is the most important complication of gonococcal, chlamydial, and non-specific infections in women. Between 1968 and 1977 the number of patients with acute PID admitted to hospitals in England and Wales rose by $50 \% 0^{1}$ and in 1977 reached 10960 , representing 92000 hospital-bed days at a cost of nearly $£ 7$ million (1981 prices). In the United States the direct costs of hospital admissions alone are calculated at nearly US\$400 million annually. ${ }^{2}$ Furthermore, a much larger number of cases is managed on an ambulant basis, for which no routine statistics are available.

This increase in acute disease is presumably associated with an increase in long-term complications and morbidity. Of these, sterility is the most serious and the best documented, but in addition patients are susceptible to recurrent pelvic pain, dysmenorrhoea, other menstrual disorders, chronic ill health, and can often become "depressed and embittered with life" after an attack of PID..$^{3-4}$ Even though these long-term sequelae are recognised, most

Address for reprints: Professor M W Adler, Academic Department of Genitourinary Medicine, Middlesex Hospital Medical School, London W1N 8AA

Accepted for publication 30 December 1981 descriptions are founded on clinical impression. The more scientific studies of patients with PID are based on women returning to hospital, concentrate mainly on the two features of pain and infertility, and often do not use controls. Thus, we decided to undertake a study to describe the morbidity associated with PID in wider terms than hitherto and to compare any changes or events with those observed in a group of controls.

\section{Patients and methods}

Female patients aged 15-44 inclusive were included in the study when admitted with presumed acute PID under the care of gynaecologists to one of five hospitals in London (Middlesex Hospital, Soho Hospital, St Mary's Hospital, Samaritan Hospital, and Central Middlesex Hospital).

After discussion with all participating clinicians a check list of clinical diagnostic features was drawn up which took account of their current diagnostic criteria and those used in previous studies. ${ }^{5-7}$ These were: constant lower abdominal pain, cervical motion tenderness, adnexal tenderness, uterine tenderness, severe lower abdominal tenderness, purulent vaginal discharge, and pyrexia. All of these were graded by severity and the level of pyrexia measured.

Patients were excluded from the study if they had a previous history of PID, had received any antimicrobial chemotherapy for the current episode or in the previous four weeks, or had undergone a termination of pregnancy, aborted, or given birth in the previous six months. 
BACTERIOLOGICAL SPECIMENS

The doctor admitting any patient considered suitable for the study collected specimens for the isolation of Neisseria gonorrhoeae and Chlamydia trachomatis in a standard manner. Material from the cervix and urethra was inoculated directly on to plates of Columbia blood agar for the isolation of $N$ gonorrhoeae. These were transported to our own laboratory for examination. Antichlamydial antibody titres in serum and cervical and urethral fluid may be correlated with infection. ${ }^{8-9}$ Specimens were taken from the cervix and urethra with specially designed micro-sponges, sent to the Institute of Ophthalmology, London, and examined by Professor S Darougar.

\section{INITIAL AND FOLLOW-UP INTERVIEWS}

Each patient in whom the diagnosis of PID was made was approached by a doctor or nurse from the research team as soon as possible after admission; if the patient agreed to take part in the study an initial interview was carried out with a structured questionnaire. After discharge from hospital, patients were followed up for about 21 months and interviewed at home by a nurse or doctor at five-monthly intervals. Any medical events or changes in social or marital state and sexual intercourse since the previous interview were recorded on a schedule similar to that used at the first interview.

\section{CONTROL GROUP}

Each patient in the study was matched with a control by age, marital state, social class, parity, ethnic origin, and method of contraception (intrauterine device or other methods). The control group did not have gynaecological examinations or microbiological tests performed at the beginning of the study. Controls were drawn from women attending family health and planning clinics in the same areas as the hospitals in the study. They were interviewed and followed up in the same way as the patients with PID using the same questionnaire.

\section{INFORMATION COLLECTED \\ Demographic and medical}

At the initial and subsequent interviews basic demographic data and information on past and present medical, obstetric, and menstrual history were recorded; the frequency of sexual intercourse, partner change, and dyspareunia were also noted. At the follow-up interviews both groups were asked whether they had had any illness which had caused them to take time off work or alter their normal daily routine.

\section{Attitudinal and interpersonal}

In an attempt to discover underlying attitudinal causes of differences in morbidity between the patients and controls, both groups were asked to $\Rightarrow$ complete a semantic differential at each of the fives? interviews. ${ }^{10}$ Each patient was asked to rate certaino concepts on a set of seven-point bipolar adjectivalo scales in order to measure the meaning the concepts $\frac{\bar{c}}{\text {. }}$ had for them. Four concepts were rated: "myself", $\mathbb{\circ}$ "my sexual partner", "sexual intercourse", ando "work". The first two concepts, rated on sixteen" scales, represented general and sexual evaluation and. anxiety; the third concept reflected evaluation and $\overrightarrow{-}$ anxiety while the fourth represented general ${ }^{\omega}$ evaluation, anxiety, and motivation.

At each interview, a rating of marital adjustmentor was made by the interviewer for those women in both $\omega_{\omega}^{\infty}$ groups who had a steady partner, either husband or $-\vec{r}$ boyfriend. Ratings of sexual and work adjustment were also made. Fuller details of the methods used to음 obtain these ratings are available elsewhere. ${ }^{11}$

ANALYSIS OF FOLLOW-UP DATA

Life table analysis was the obvious method of choiceco for comparing morbidity in the two groups. Now information on the exact timing of reported events was recorded, however. Although it could have beeno assumed, for example, that these events had occurred at the mid-point of the interval since the lasto interview, any such assumptions would have been? subject to considerable error. We therefore decided that the cumulative rates of occurrence for each typeo of event would be compared between the two groups at each follow-up interview. Thus, for instance, the cumulative rate for abdominal pain in the group with PID at the second follow-up interview was found by? taking the number of patients who had reportedo abdominal pain at the first or second follow-up. interviews and dividing it by the number of patientsô who remained in the study to the second follow up. Women who reported abdominal pain at the firsto follow-up interview, but were lost at the second, were excluded from the calculation of this rate.

All the differences reported between the two groups were statistically significant at the $5 \%$ level. जr

\section{Results}

Seventy-eight patients with PID and 77 controls were entered into the study.

PRESENTING FEATURES AND LABORATORY RESULTS

Patients with PID

Lower abdominal pain and adnexal tenderness weree the commonest presenting features and were found 
in over $90 \%$ of patients, followed by cervical motion tenderness $(81 \%)$ and uterine tenderness on bimanual examination (70\%). In addition, $31(\mathbf{4 0 \%})$ women were pyrexial $\left(>37 \cdot 2^{\circ} \mathrm{C}\right)$. Only $8 \%$ of women had less than four of the seven presenting features recorded, while over half $(51 \%)$ had six or all seven.

$N$ gonorrhoeae was isolated from $14(18 \%)$ patients and $C$ trachomatis from four (5\%). A further 20 patients had one or more raised antichlamydial antibody titres, suggesting an acute infection. The remaining $40(51 \%)$ patients in whom no organisms or raised antibody titres were found were diagnosed clinically as having non-specific PID. The erythrocyte sedimentation rate was raised in 10 of the 28 women for whom it was recorded; the highest rate was $71 \mathrm{~mm} /$ first hour. Twenty-eight of the 45 patients in whom a white blood cell count was made had values $>10 \times 10^{9} / 1$.

\section{DEMOGRAPHIC DATA AND MEDICAL HISTORY AT INITIAL INTERVIEW \\ Patients and controls}

The mean age of women with PID was $24 \cdot 0$ years (standard error 0.65 ), and that of the control group 23.3 years (standard error 0.55 ). No statistically significant differences were found between the patients and controls in relation to marital state or social class. Significantly more of the patients with PID were of African, Middle Eastern, or mixed origin while fewer were Caucasian. Further analysis, however, showed the ethnic origin was not related to the occurrence of events or changes during the follow-up period.

Sixty-four (82\%) women with PID and $68(88 \%)$ women in the control group had regular sexual partners; the mean numbers of sexual partners in the previous year were $2 \cdot 0$ and 1.4 respectively. Patients with PID often reported that they were using no contraceptive method; the controls, however, were significantly more likely to be taking the contraceptive pill.

TABLE I Number of women interviewed at each follow up and mean length of time between entry and each follow-up interview

\begin{tabular}{|c|c|c|c|c|c|c|}
\hline \multirow[b]{3}{*}{ Follow up } & \multicolumn{3}{|c|}{ Patients } & \multicolumn{3}{|c|}{ Controls } \\
\hline & \multicolumn{2}{|c|}{ Interviewed } & \multirow{2}{*}{$\begin{array}{l}\text { Mean time } \\
\text { after entry } \\
\text { (months } \\
\pm S E)\end{array}$} & \multicolumn{2}{|c|}{ Interviewed } & \multirow{2}{*}{$\begin{array}{l}\text { Mean time } \\
\text { after entry } \\
\text { (months } \\
\pm S E)\end{array}$} \\
\hline & No & $\%$ & & No & $\%$ & \\
\hline $\begin{array}{l}\text { First } \\
\text { Second } \\
\text { Third } \\
\text { Fourth }\end{array}$ & $\begin{array}{l}61 \\
56 \\
53 \\
46\end{array}$ & $\begin{array}{l}78 \cdot 2 \\
71 \cdot 8 \\
67 \cdot 9 \\
59 \cdot 0\end{array}$ & $\begin{array}{r}5 \cdot 77 \pm 0 \cdot 24 \\
11 \cdot 52 \pm 0 \cdot 33 \\
16 \cdot 85 \pm 0 \cdot 35 \\
21 \cdot 33 \pm 0 \cdot 42\end{array}$ & $\begin{array}{l}65 \\
61 \\
61 \\
53\end{array}$ & $\begin{array}{l}84 \cdot 4 \\
79 \cdot 2 \\
79 \cdot 2 \\
68 \cdot 8\end{array}$ & $\begin{array}{r}5 \cdot 94 \pm 0 \cdot 29 \\
11 \cdot 74 \pm 0 \cdot 35 \\
16 \cdot 92 \pm 0 \cdot 44 \\
21 \cdot 70 \pm 0 \cdot 39\end{array}$ \\
\hline
\end{tabular}

$\mathrm{SE}=$ standard error
No differences were found between the two groups in the occurrence or number of past pregnancies and the mean number of children, miscarriages, stillbirths, and terminations.

As expected, the patients with PID had had significantly more abdominal pain (other than menstrual pain) in the preceding three months than the controls. They were also more likely to describe their periods as heavy and to complain of dysmenorrhoea and dyspareunia in the previous three months. The proportions of women in the two groups who had consulted their general practitioner in the previous three months were similar, $58 \%$ for those with PID and $48 \%$ for the controls.

\section{FINDINGS ON FOLLOW UP}

Follow-up rate

Forty-six (59\%) of the 78 women with PID originally entered remained in the study to the end, as did 53 $(69 \%)$ of the 77 women in the control group (table I). The findings on follow up could have been potentially biased by differences between the women who were lost to follow up and those who were not. Within each group, therefore, women who were interviewed at the fourth follow up were compared with those who were lost by that time in respect to all the variables measured at the initial interview.

In the group with PID, the follow-up rate was related to ethnic origin. It was highest among West Indians (84\%) and lowest among women of "other" ethnic origin $(29 \%)$. This meant, however, that by the time the study was completed the differences in ethnic origin between the group with PID and the control group (described earlier) were no longer statistically significant.

\section{Abdominal operations}

Women who had had PID were significantly more likely to have had an abdominal operation during the 21-month follow-up period than women in the control group (table II). The difference was most

TABLE II Abdominal operations: rates between each interview and cumulative rates for patients and controls

\begin{tabular}{lrll}
\hline & $\begin{array}{l}\text { Patients } \\
(\%)\end{array}$ & $\begin{array}{l}\text { Controls } \\
(\%)\end{array}$ & $\begin{array}{l}\text { Significance } \\
\text { of } \\
\text { difference }\end{array}$ \\
\hline Rates between: & & & \\
Entry and 1st follow up & 16.4 & 0.0 & $\mathrm{P}<0.01$ \\
1st and 2nd follow up & 5.4 & 4.9 & $\mathrm{NS}$ \\
2nd and 3rd follow up & 13.2 & 1.6 & $\mathrm{P}<0.02$ \\
3rd and 4th follow up & 4.3 & 0.0 & $\mathrm{NS}$ \\
Cumulative rate at: & 16.4 & 0.0 & $\mathrm{P}<0.01$ \\
Ist follow up & 19.6 & 4.9 & $\mathrm{P}<0.05$ \\
2nd follow up & 30.2 & 6.6 & $\mathrm{P}<0.01$ \\
3rd follow up & 23.9 & 5.7 & $\mathrm{P}<0.05$ \\
4th follow up & & & \\
\hline
\end{tabular}

NS $=$ not significant 
TABLE III Abdominal pain: rates between each interview and cumulative rates for patients and controls

\begin{tabular}{llll}
\hline & $\begin{array}{l}\text { Patients } \\
(\%)\end{array}$ & $\begin{array}{l}\text { Controls } \\
(\%)\end{array}$ & $\begin{array}{l}\text { Significance } \\
\text { of } \\
\text { difference }\end{array}$ \\
\hline Rates between: & & & \\
Entry and 1st follow up & 55.7 & $9 \cdot 2$ & $\mathrm{P}<0.001$ \\
1st and 2nd follow up & 37.5 & 9.8 & $\mathrm{P}<0.001$ \\
2nd and 3rd follow up & 37.7 & 6.6 & $\mathrm{P}<0.001$ \\
3rd and 4th follow up & 19.6 & 5.7 & $\mathrm{NS}$ \\
Cumulative rate at: & & & \\
1st follow up & 55.7 & 9.2 & $\mathrm{P}<0.001$ \\
2nd follow up & 67.9 & 14.8 & $\mathrm{P}<0.001$ \\
3rd follow up & 73.6 & 18.0 & $\mathrm{P}<0.001$ \\
4th follow up & 73.9 & 22.6 & $\mathrm{P}<0.001$ \\
\hline
\end{tabular}

NS $=$ not significant

noticeable in the first five months after entry to the study, when $10(16 \%)$ patients had an abdominal operation compared with none of the controls. The commonest operation was laparoscopy, which was carried out on six of the 10 patients during this period. During the whole follow-up period, 22 abdominal operations were performed on the patients with PID, and laparoscopy was still the commonest procedure (10 out of the 22 operations).

By the time they reached the fourth follow-up interview, three-quarters of the patients but less than one-quarter of the controls had reported abdominal pain other than dysmenorrhoea (table III). Reporting rates were higher in the group with PID throughout the follow-up period. At all interviews except the last the patients were also significantly more likely to complain that sexual intercourse had become painful (table IV).

\section{Menstrual history}

At each follow up, the women were asked whether they had noticed any change in their periods since the preceding interview and if so to specify what change

TABLE IV Pain during sexual intercourse: rates between each interview and cumulative rates for patients and controls

\begin{tabular}{|c|c|c|c|}
\hline & $\begin{array}{l}\text { Patients } \\
(\%)\end{array}$ & $\begin{array}{l}\text { Controls } \\
(\%)\end{array}$ & $\begin{array}{l}\text { Significance } \\
\text { of } \\
\text { difference }\end{array}$ \\
\hline \multicolumn{4}{|l|}{ Rates between: } \\
\hline Entry and ist follow up & $29 \cdot 1$ & $3 \cdot 4$ & $\mathrm{P}<0.001$ \\
\hline 1 st and 2 nd follow up & $21 \cdot 2$ & $1 \cdot 7$ & $P<0.01$ \\
\hline 2nd and 3rd follow up & $23 \cdot \overline{4}$ & $5 \cdot 1$ & $P<0.02$ \\
\hline 3rd and 4th follow up & $17 \cdot 1$ & $7 \cdot 5$ & NS \\
\hline \multicolumn{4}{|l|}{ Cumulative rate at: } \\
\hline 1 st follow up & $29 \cdot 1$ & $3 \cdot 4$ & $\mathrm{P}<0.001$ \\
\hline 2nd follow up & $37 \cdot 0$ & $5 \cdot 0$ & $P<0.001$ \\
\hline 3rd follow up & $43 \cdot 4$ & $10 \cdot 0$ & $\mathrm{P}<0.001$ \\
\hline 4th follow up & $41 \cdot 3$ & $13 \cdot 2$ & $P<0.01$ \\
\hline
\end{tabular}

NS $=$ not significant
TABLE $\mathrm{v}$ Change in periods: rates between each interview and cumulative rates for patients and controls

\begin{tabular}{|c|c|c|c|}
\hline & $\begin{array}{l}\text { Patients } \\
(\%)\end{array}$ & $\begin{array}{l}\text { Controls } \\
\text { (\%) }\end{array}$ & $\begin{array}{l}\text { Significance } \\
\text { of } \\
\text { difference }\end{array}$ \\
\hline $\begin{array}{l}\text { Rates between: } \\
\text { Entry and 1st follow up } \\
\text { 1st and 2nd follow up } \\
\text { 2nd and 3rd follow up } \\
\text { 3rd and 4th follow up }\end{array}$ & $\begin{array}{l}40 \cdot 8 \\
39 \cdot 2 \\
43 \cdot 1 \\
38 \cdot 5\end{array}$ & $\begin{array}{l}29 \cdot 1 \\
12 \cdot 2 \\
22 \cdot 4 \\
19 \cdot 1\end{array}$ & $\begin{array}{l}\text { NS } \\
P<0.01 \\
P<0.05 \\
\text { NS }\end{array}$ \\
\hline $\begin{array}{l}\text { Cumulative rate at: } \\
\text { 1st follow up } \\
\text { 2nd follow up } \\
\text { 3rd follow up } \\
\text { 4th follow up }\end{array}$ & $\begin{array}{l}40 \cdot 8 \\
60 \cdot 5 \\
74 \cdot 3 \\
80 \cdot 0\end{array}$ & $\begin{array}{l}29 \cdot 1 \\
28 \cdot 6 \\
35 \cdot 7 \\
44 \cdot 1\end{array}$ & $\begin{array}{l}\text { NS } \\
P<0.01 \\
P<0.01 \\
P<0.01\end{array}$ \\
\hline
\end{tabular}

had occurred. Some women in both groups becamẹ pregnant during the study and were therefore excluded from the analysis of menstrual changes. At the first follow up, there was no significant differ-9 ence between the groups in the proportion of women who reported a change. Thereafter, however, thereporting rates were consistently higher in the groupd with PID (table V). By the end of the study, $80 \%$ of patients but only $44 \%$ of controls had said that theiro periods had changed in some way. The patients were more likely to report longer and more painfulo periods.

\section{Obstetric history}

By the end of the 21-month follow-up period, $14 \stackrel{乛}{\circ}$ $(30 \%)$ patients and $19(36 \%)$ controls had becomeo pregnant. This difference was not statistically signifi- 3 cant. Similarly, there were no significant differences in rates of conception, miscarriage, stillbirth, and ectopic pregnancies between the patients with PID? and controls.

\section{Medical consultation}

Approximately $50 \%$ of women in both groups stated that they had consulted their general practitionero between each interview, up to the third follow up (table VI). Between the third and fourth follow ups, however, $29(63 \%)$ patients had contacted their doctor compared with only $20(38 \%)$ of the controls. When the cumulative rates were examined, paradoxi- N cally they were higher in the control group than in the्w group with PID, with the difference almost reachingo statistical significance at the fourth follow up. This indicates that within the group with PID a number of women attended their doctor repeatedly but that? within the control group a greater number of womeno did so on fewer occasions.

Seventy per cent of patients visited a hospita迎 between their initial and the first follow-up interviews compared with only $20 \%$ of controls, but no differ- 
TABLE VI Consultation with general practitioner: rates between each interview and cumulative rates for patients and controls

\begin{tabular}{|c|c|c|c|}
\hline & $\begin{array}{l}\text { Patients } \\
(\%)\end{array}$ & $\begin{array}{l}\text { Controls } \\
(\%)\end{array}$ & $\begin{array}{l}\text { Significance } \\
\text { of } \\
\text { difference }\end{array}$ \\
\hline $\begin{array}{l}\text { Rates between: } \\
\text { Entry and 1st follow up } \\
\text { 1st and 2nd follow up } \\
\text { 2nd and 3rd follow up } \\
\text { 3rd and 4th follow up }\end{array}$ & $\begin{array}{l}50 \cdot 8 \\
44 \cdot 6 \\
52 \cdot 8 \\
63 \cdot 0\end{array}$ & $\begin{array}{l}50 \cdot 8 \\
54 \cdot 1 \\
44 \cdot 3 \\
37 \cdot 7\end{array}$ & $\begin{array}{l}\text { NS } \\
\text { NS } \\
\text { NS } \\
P<0.05\end{array}$ \\
\hline $\begin{array}{l}\text { Cumulative rate at: } \\
\text { 1st follow up } \\
\text { 2nd follow up } \\
\text { 3rd follow up } \\
\text { 4th follow up }\end{array}$ & $\begin{array}{l}50 \cdot 8 \\
62 \cdot 5 \\
79 \cdot 2 \\
87 \cdot 0\end{array}$ & $\begin{array}{l}50 \cdot 8 \\
77 \cdot 0 \\
88 \cdot 5 \\
96 \cdot 2\end{array}$ & $\begin{array}{l}\text { NS } \\
\text { NS } \\
\text { NS } \\
\text { NS }\end{array}$ \\
\hline
\end{tabular}

NS $=$ not significant

ences in hospital visiting rates between the groups were found thereafter. Similarly, more patients $(20 \%)$ than controls $(6 \%)$ were admitted to hospital in the first five months of the follow-up period. The commonest reason for admission was abdominal pain (eight of the 12 admissions). The cumulative rate for hospital admission was significantly higher in the group with PID than in the control group at the fourth follow up (54\% compared with $28 \%$ ). Again, the commonest cause of admission was abdominal pain. This apparent difference may well have been caused by the loss to follow up of women who had been admitted to hospital in the control group rather than by a genuine difference between the groups.

\section{Change in daily routine}

Women in both groups were asked whether they had had to alter their normal day-to-day routine because of any illness they had had since their previous interview. In the first five months after the start of the study, $17(28 \%)$ patients but only two $(3 \%)$ controls stated that they had had to do so. The cumulative rates were significantly higher in the group with PID

TABLE VII Alteration of normal daily routine because of illness: rates between each interview and cumulative rates for patients and controls

\begin{tabular}{llll}
\hline & $\begin{array}{l}\text { Patients } \\
(\%)\end{array}$ & $\begin{array}{l}\text { Controls } \\
(\%)\end{array}$ & $\begin{array}{l}\text { Significance } \\
\text { of } \\
\text { difference }\end{array}$ \\
\hline Rates between: & & & \\
Entry and 1st follow up & 27.9 & $3 \cdot 1$ & $\mathrm{P}<0.001$ \\
1st and 2nd follow up & 16.1 & 4.9 & $\mathrm{NS}$ \\
2nd and 3rd follow up & 7.5 & 4.9 & $\mathrm{NS}$ \\
3rd and 4th follow up & 28.3 & $11 \cdot 3$ & $\mathrm{NS}$ \\
Cumulative rate at: & & & \\
1st follow up & 27.9 & 3.1 & $\mathrm{P}<0.001$ \\
2nd follow up & 33.9 & 6.6 & $\mathrm{P}<0.001$ \\
3rd follow up & 37.7 & 9.8 & $\mathrm{P}<0.001$ \\
4th follow up & 58.7 & 15.1 & $\mathrm{P}<0.001$ \\
\hline
\end{tabular}

NS $=$ not significant throughout the follow-up period (table VII). By the fourth follow-up interview, $59 \%$ of patients had reported a change in their routine because of illness compared with only $15 \%$ of controls.

Between the initial and the first follow-up interviews, $13(21 \%)$ patients said that they had had to take time off work compared with only two $(3 \%)$ controls; $15 \%$ of women with PID but only $2 \%$ of controls said that they had had to stay in bed. Between the first and second follow-up interviews, $16 \%$ of patients said they had had to stay in bed compared with $3 \%$ of women in the control group. All of these differences were statistically significant.

SEMANTIC DIFFERENTIAL SCORES AND ADJUSTMENT RATINGS

There were no consistent differences between the patients and controls in relation to group mean scores for each dimension of attitude towards the four concepts. The adjustment ratings also differed little between the groups. At the first follow-up interview, $93 \%$ of the controls had their marital adjustment rated as satisfactory compared with only $69 \%$ of the patients. Ratings of sexual adjustment were higher among the controls at the initial and the first follow-up interviews, but the groups did not differ thereafter. Satisfactory work adjustment was recorded for $82 \%$ of women with PID at the third follow up but for $57(95 \%)$ of the 60 controls.

\section{Discussion}

Pelvic inflammatory disease can have profound physical and psychological effects on patients, a number of which have been measured in this study. In some instances similarities were evident for both patients with PID and the controls; in others, some differences were seen immediately after discharge from hospital (but they did not persist) and others continued for longer.

Infertility, pregnancy wastage, and ectopic pregnancy are recognised consequences of PID. ${ }^{12-15}$ This study did not show any variation between patients with PID and the controls in their ability to become pregnant or the likelihood of their having a miscarriage or ectopic pregnancy by the end of the 21-month follow-up period. Substantial differences have been found, with periods of follow up ranging from 4-9.5 years. ${ }^{312} 16$ Compared with these studies, our follow-up time was extremely short and probably too short after the acute episode to show any variation which might have existed. In particular, a short follow-up period may militate against the finding of any dissimilarities, since patients may decide to be advised to postpone attempts to become pregnant voluntarily until "things have settled down". 
In some instances the differences between patients and controls were most pronounced at the first follow-up interview at 5-6 months after entry. Thus, significantly more patients than controls had visited hospital as outpatients, been admitted to hospital, and had undergone abdominal operations. These findings are not surprising since patients tend to be followed up and observed most intensely immediately after being in hospital, and any persistence of symptoms may be investigated, especially by laparoscopy, as occurred in this study. Significant differences were also found between patients and controls in relation to alteration of their normal daily routine and time off work at the first interview but not thereafter. Again, this is not an unexpected finding since patients will be convalescing after their discharge from hospital.

The cumulative rates for outpatient visits, hospital admissions, abdominal operations, and alteration of daily routine were significantly higher in the group with PID than in the controls. Loss to follow up among the controls may have accounted for some of these variations. Even so, the fact that $89 \%$ of patients were seen as outpatients, $54 \%$ were admitted to hospital, and $24 \%$ underwent abdominal operations represents a substantial cost to the National Health Service. Similarly, the alteration of normal daily routine in $59 \%$ of patients during the course of the study is a cost to the individual and to the nation. The economic consequences of illness and treatment are not confined to the Health Service; the patient's household can be affected economically in a variety of ways during admission to hospital and after discharge.

Some of the features measured showed differences between the patients and controls both at early and later follow-up interviews and cumulatively. These were abdominal pain (other than period pain), changes in menstruation (longer and more painful), and pain on sexual intercourse; the cumulative rates for each in patients with PID were $74 \%, 80 \%$, and $41 \%$ respectively. Weström ${ }^{3}$ has reported a lower rate for abdominal pain after PID; he indicated that $18 \%$ of patients had pain lasting for longer than six months causing them to seek medical advice, while Falk $^{5}$ reported that $17 \%$ of patients had chronic pain. Our figures were substantially higher. This may be because we were measuring pain which was not necessarily taken to a doctor and was thus less severe; furthermore, patients were never asked whether they had had pain for a specific length of time, such as six months. We could not assess the degree of discomfort experienced by the patients with abdominal pain or the extent to which it impinged on their lives. A proportion of the patients with PID were readmitted to hospital, usually because of abdominal pain, and the commonest procedure was laparoscopy. Con-西 tinuing pain which requires admission to hospital presents a substantial diagnostic clinical problem. Over 10000 women a year have laparoscopic examination for abdominal pain. ${ }^{17}$

Increased pain associated with periods was also experienced by the patients with PID, and the $\frac{\overline{\underline{\sigma}}}{\text {. }}$ reporting rates for menstrual changes after PID were higher in the patients than in the controls throughout the follow-up period. Again the degree of discomfortw and disruption of "normal" living cannot be judged, $\overrightarrow{-}$ but some patients will require medication and be forced to alter their normal routines.

The final difference between the patients and controls concerned dyspareunia. This feature of PID is not well documented. The degree of disruptionis that it causes cannot be judged, even though it ${ }^{2}$ continued in one-fifth of patients after the initial $r$ acute disease episode. Although both sexual and marital adjustment were reduced in the patients at? the first follow up, this did not persist, and no majorattitudinal differences in the concepts "my sexuale partner" and "sexual intercourse" were detected by use of the semantic differential. This may mean $\overrightarrow{0}$ either that dyspareunia was not severe enough too interfere with satisfactory sexual relationships or that patients learnt to tolerate their pain without com-O plaining.

The increase in acute PID and the related chronico sequelae mean that this condition has now replacedo syphilis as the STD with the most serious long-term consequences.

The study was supported as part of a research contract from the Medical Research Council. We wish to thank all the clinicians and patients who tooks? part. We are particularly grateful to our two research nurses (Julia Vaughan-Smith and Jasmine Peel), who 3 . carried out the interviews, and to Professor So Darougar for examining the chlamydial specimens.

\section{References}

1. Adler MW. Trends for gonorrhoea and pelvic inflammatory disease in England and Wales and for gonorrhoea in a defined population. Am J Obstet Gynecol 1980; 138:901.

2. Curran $\mathrm{JW}$. Economic consequences of pelvic inflammatory $\omega$ disease in the United States. Am J Obstet Gynecol 1980;138:

3. Weström L. Effect of acute pelvic inflammatory disease on fertility. Am J Obstet Gynecol 1975;121:707.

4. King A, Nicol C. Venereal Diseases. 3rd edition. London: Baillière Tindall, 1975:207.

5. Falk V. Treatment of acute non-tuberculous salpingitis with antibiotics alone and in combination with glucocorticoids. A음 prospective double-blind controlled study of the clinical course $\overparen{D}$ and prognosis. Acta Obstet Gynecol Scand $1965 ; 44$ suppl 6:3. $\frac{\text { ? }}{\text { Th }}$

6. Wright NH, Laemmle S. Acute pelvic inflammatory disease in an indigent population. Am J Obstet Gynecol 1968; 101:979. 
7. Targum SD, Wright NH. Association of the intrauterine device and pelvic inflammatory disease: a retrospective pilot study. Am J Epidemiol 1974; 100: 262.

8. Treharne JD, Dines RJ, Darougar S. Serological responses to chlamydial ocular and genital infections in the United Kingdom and Middle East. In Non-gonococcal Urethritis and Related Infections. Hobson D, Holmes KK, eds. Washington DC: American Society of Microbiology, 1977;249.

9. Treharne JD, Darougar S, Simmons PH, Thin RN. Rapid diagnosis of chlamydial infection of the cervix. $\mathrm{Br} J$ Vener Dis 1978;54:404.

10. Osgood CE. The Measurement of Meaning. Urbana: University of Illinois Press, 1957.

11. Greer HS, Lal S, Lewis SC, Belsey EM, Beard RW. Psychosocial consequences of therapeutic abortion. $B r J$ Psychiatry 1976; 128: 74

12. Hedberg E, Speyz SO. Acute salpingitis. Views on prognosis and treatment. Acta Obstet Gynecol Scand 1958;37:131.
13. World Health Organisation. The epidemiology of infertility. Technical Report Series 582. Geneva: WHO, 1975.

14. Weström L, Iosif S, Svensson L, Mårdh P-A. Infertility after acute salpingitis: Results of treatment with different antibiotics. In: Sexually Transmitted Disease Symposium Proceedings. New York: Science and Medicine Publishing Co, 1979:5.

15. Westrơm L, Mårdh P-A. Reproductive events after acute salpingitis. In: Swedish Studies on Infertility and Ectopic Pregnancy. Washington DC: National Institute of Health, 1980.

16. Holtz F. Klinische studien uber die nicht tuberkulose salpingoloophritis. Acta Obstet Gynecol Scand 1930;10 suppl 1.

17. Working Party of the Confidential Enquiry into Gynaecological Laparoscopy. Gynaecological laparoscopy. Br J Obstet Gynaecol 1978; 85:401. 